\title{
Isolation and structural identification of a new T1-conotoxin with unique disulfide connectivities derived from Conus bandanus
}

\author{
Nguyen Bao1,* (1), Jean-Pière Lecaer ${ }^{2}$, Ngo Dang Nghia ${ }^{3}$, Phan Thi Khanh Vinh ${ }^{1}$ \\ ${ }^{1}$ Faculty of Food Technology, Nha Trang University, 02 Nguyen Dinh Chieu, Nha Trang, Khanh Hoa, Vietnam. \\ ${ }^{2}$ Institut de Chimie des Substances Naturelles, Centre de Recherche de Gif, FRC3115, UPR 2301, F-91198 Gif-sur-Yvette, France. \\ ${ }^{3}$ Institute of Biotechnology and Environment, Nha Trang University, 02 Nguyen Dinh Chieu, Nha Trang, Khanh Hoa, Vietnam.
}

\section{Keywords:}

T1-subfamily conotoxin

Conus bandanus

$\mathrm{Bn} 5 \mathrm{a}$

Disulfide connectivity

Cone snail venom

\begin{abstract}
Background: Conopeptides are neuropharmacological peptides derived from the venomous salivary glands of cone snails. Among 29 superfamilies based on conserved signal sequences, T-superfamily conotoxins, which belong to the smallest group, include four different frameworks that contain four cysteines denominated I, V, X and XVI. In this work, the primary structure and the cysteine connectivity of novel conotoxin of Conus bandanus were determined by tandem mass spectrometry using collisioninduced dissociation.
\end{abstract}

Methods: The venom glands of $C$. bandanus snails were dissected, pooled, and extracted with $0.1 \%$ trifluoroacetic acid in three steps and lyophilized. The venom was fractionated and purified in an HPLC system with an analytical reversed-phase $\mathrm{C}_{18}$ column. The primary peptide structure was analyzed by MALDI TOF MS/MS using collision-induced dissociation and confirmed by Edman's degradation. The peptide's cysteine connectivity was determined by rapid partial reduction-alkylation technique.

Results: The novel conotoxin, $\mathrm{NGC}_{1} \mathrm{C}_{2}(\mathrm{I} / \mathrm{L}) \mathrm{VREC}_{3} \mathrm{C}_{4}$, was firstly derived from $d e$ novo sequencing by MS/MS. The presence of isoleucine residues in this conotoxin was confirmed by the Edman degradation method. The conotoxin, denominated Bn5a, belongs to the T1-subfamily of conotoxins. However, the disulfide bonds $\left(\mathrm{C}_{1}-\mathrm{C}_{4} / \mathrm{C}_{2}-\mathrm{C}_{3}\right)$ of Bn5a were not the same as found in other T1-subfamily conopeptides but shared common connectivities with T2-subfamily conotoxins. The T1-conotoxin of C. bandanus proved the complexity of the disulfide bond pattern of conopeptides. The homological analysis revealed that the novel conotoxin could serve as a valuable probe compound for the human-nervous-system norepinephrine transporter.

Conclusion: We identified the first T1-conotoxin, denominated $\mathrm{Bn} 5 \mathrm{a}$, isolated from C. bandanus venom. However, Bn5a conotoxin exhibited unique $\mathrm{C}_{1}-\mathrm{C}_{4} / \mathrm{C}_{2}-\mathrm{C}_{3}$ disulfide connectivity, unlike other T1-conotoxins $\left(\mathrm{C}_{1}-\mathrm{C}_{3} / \mathrm{C}_{2}-\mathrm{C}_{4}\right)$. The structural and homological analyses herein have evidenced novel conotoxin Bn5a that may require further investigation.

\footnotetext{
* Correspondence: bao@ntu.edu.vn
} https://doi.org/10.1590/1678-9199-JVATITD-2019-0095 Received: 03 December 2019; Accepted: 15 April 2020; Published online: 08 May 2020 


\section{Background}

Conopeptides (conotoxins) are peptides derived from the venomous salivary glands of cone snails consisting of 8-84 amino acids and zero to five disulfide bridges. They are neuropharmacological probes and pharmacological development for G-protein-coupled receptors, ion channels $\left(\mathrm{K}^{+}, \mathrm{Na}^{+}, \mathrm{Ca}^{2+}\right.$, and neurotransmitter receptors (such as $\mathrm{N}$-methyl-d-aspartate receptor, 5-hydroxytryptamine, nicotinic acetylcholine receptor) with high degrees of specificity and potency [1,2]. Recently, conopeptides were grouped into 29 superfamilies, based on conserved signal sequences with or without specific cysteine frameworks within each superfamily [3]. Among these, T-superfamily conotoxins that belong to the smallest group, typically 10-16 amino-acid residues in length, are widely distributed in all feeding types of Conus snails. These conotoxins include four different cysteine frameworks that contain four cysteines, namely “-CC-C-C-”(I), “-CC-CC-” (V), “-CC-C.[PO] C-" (X) and "-C-C-CC-" (XVI) [4].

So far, there are approximately 40 known sequences with cysteine framework $\mathrm{V}$ for all three species-based diet types, specifically piscivore, vermivore and molluscivore. Some T-conotoxins had been reported as pharmacological targets such as somatostatin receptors like CnVA [5], sodium channels like LtVd [6], presynaptic calcium channels like TxVA [7], and neuronal nicotinic acetylcholine receptors like TxVC [8]. All of them possess $\mathrm{C}_{1}-\mathrm{C}_{3} / \mathrm{C}_{2}-\mathrm{C}_{4}$ cysteine connectivities. Biological activities of conotoxins depend strictly on the peptide sequence and pairing of the cysteines. Matrix-assisted laser desorption/ ionization time of flight (MALDI-TOF) mass spectrometry spectrometers combined with Edman degradation can provide the complete peptide sequence information from a small amount of sample. The fragmentation capabilities, such as collisioninduced dissociation (CID) conferred by MALDI-TOF MS [9], along with the rapid partial reduction-alkylation procedure [10], are especially useful for determination of disulfide connectivity. In the present work, the reserved-phase chromatography was employed to enrich T-superfamily components from venom of mollusk-hunting cone snail species (C. bandanus). The sequence assignment of the peptide was determined using MALDI mass spectrometry. Furthermore, we established the unusable disulfide pairing of a novel T1-subfamily conotoxin using the partial reduction-alkylation procedure.

\section{Methods}

\section{Isolation and purification of conopeptides}

The specimens of each C. bandanus were collected from seawater at Ke Ga reef in Nha Trang Bay (Vietnam) and were frozen at $-80{ }^{\circ} \mathrm{C}$. The venom of the whole $C$. bandanus apparatus was dissected, extracted with $\mathrm{H}_{2} \mathrm{O} / 0.1 \%$ trifluoroacetic acid (TFA) in three steps, and lyophilized. The venom powder was dissolved and subjected to HPLC fractionation with a Shimadzu LC-class
10 HPLC system. The venom extract was purified by separation in an analytical reversed-phase $\mathrm{C}_{18}$ column (Vydac, $300 \AA$, $5 \mu \mathrm{m}$, $4.6 \mathrm{~mm}$ i.d.x250 $\mathrm{mm})$ with solution $\mathrm{A}(0.1 \% \mathrm{TFA})$ and solution $\mathrm{B}\left(0.1 \% \mathrm{TFA}\right.$ in $\left.90 \% \mathrm{CH}_{3} \mathrm{CN}\right)$ as the mobile phase. The flow rate was maintained at $1 \mathrm{~mL} . \mathrm{min}^{-1}$ with gradient program $(0 \%$ of solution B for $10 \mathrm{~min}$, then $0-50 \%$ of B for $45 \mathrm{~min}$ ). The detection of peptides was monitored at the wavelength $220 \mathrm{~nm}$. Further purification steps were carried out using gradients $(8-13 \%$ of $\mathrm{B}$ in $7.5 \mathrm{~min}$, then $13-18 \%$ of $\mathrm{B}$ in $169.5 \mathrm{~min}$ ).

\section{Reduction and alkylation of disulfide bonds}

Twenty $\mu \mathrm{L}$ of the purified fraction was reduced by incubation for $10 \mathrm{~min}$ at $65^{\circ} \mathrm{C}$ in $40 \mu \mathrm{L}$ of $20 \mathrm{mM}$ tris (2-carboxyethyl) phosphine (TCEP) in 0.5 M 4-(2-hydroxyethyl)-1-piperazineethanesulfonic acid (HEPES). Alkylation was then achieved by the addition of $50 \mathrm{mM}$ iodoacetamide (IAA) and incubated for $30 \mathrm{~min}$ at 25 ${ }^{\circ} \mathrm{C}$ in darkness. The mixture was lastly desalted by solid-phase extraction on a ZipTip $\mathrm{C}_{18}$ column (Millipore, Billerica, MA, USA).

\section{Rapid partial reduction and alkylation procedure}

For rapid partial reduction [10], each $4 \mu \mathrm{L}$ of $\mathrm{Bn} 5 \mathrm{a}(2.15 \mathrm{mM})$ was reduced with $36 \mu \mathrm{L} 20 \mathrm{mM}$ TCEP in a $0.17 \mathrm{M}$ sodium acetate buffer, $\mathrm{pH} \sim 3.0$, for $2.5 \mathrm{~min}$, immediately alkylated by $80 \mu \mathrm{L}$ of 2.2 M IAA in 0.5 M Tri-acetate, $2 \mathrm{mM} \mathrm{Na2-EDTA} \mathrm{buffer} \mathrm{(pH}$ $\sim 8.0$ ) and incubated for $30 \mathrm{~min}$ in darkness. The whole reaction mixture was passed through an analytical $\mathrm{C}_{18}$ Vydac column to separate the different peptide forms. The eluents of different fractions were collected in Eppendorf tubes. The MALDI-TOF MS analysis was carried out to determine modified-peptide fraction(s) possessing only two carbamidomethyl cysteines. In the second reduction step, the modified peptide fractions were dried and incubated with $20 \mu \mathrm{L}$ of $20 \mathrm{mM}$ TCEP in 0.5 M HEPES ( $\mathrm{pH} \sim 7.0$ ) for $30 \mathrm{~min}$. The finally modified peptide mixture was desalted with a Zip Tip $\mathrm{C}_{18}$ column.

\section{Mass spectrometry analysis}

Mass spectrometry experiments were performed using a 4800 MALDI TOF/TOF ${ }^{\mathrm{Tm}}$ Analyzer mass spectrometer (AB Sciex, Les Ulis, France). The samples were irradiated with an Nd:YAG laser operating at $355 \mathrm{~nm}$ wavelength, producing $3 \mathrm{~ns}$ wide pulses. The instrument was externally calibrated using a peptide mixture (peptide calibration 1 and 2 from ABSciex between 700 and $3700 \mathrm{Da})$. Acquisitions were performed in positive reflection mode. For the dried-droplet sample preparation method, 0.5 $\mu \mathrm{L}$ of the sample was mixed with $0.5 \mu \mathrm{L}$ of a solution of $4 \mathrm{mg} /$ $\mathrm{ml}$ of HCCA. For MS/MS experiments, precursor ions were accelerated at $8 \mathrm{keV}$, and the MS/MS spectra were acquired using $2 \mathrm{keV}$ collision energy, with CID gas at a pressure of $3.5 \times 10^{-6}$ Torr. Mass spectra were analyzed using Data Explorer 4.9 (AB Sciex). For peptide sequence analysis, the mass tolerance of the precursor was $10 \mathrm{ppm}$ and $0.05 \mathrm{Da}$ for fragment identification. 


\section{Peptide sequencing by edman degradation}

The amino-acid sequences of the native peptide were determined by automated Edman degradation using a Procise protein sequencer (Applied Biosystem model 492, Applied Biosystem, Foster City, CA, USA). Then $2 \mu \mathrm{L}(\sim 5.7 \mathrm{mM})$ of the native peptide was dissolved in $25 \mu \mathrm{L}$ of $50 \%$ (v/v) aqueous TFA for sequencing.

\section{Results}

\section{Isolation of novel peptide from $\boldsymbol{C}$. bandanus venom}

In search of new conopeptides from the venom of C. bandanus, we have found a novel peptide containing an unusual arrangement of its disulfide connectivities. This peptide was collected from the throughput on an analytical $\mathrm{C}_{18}$ column between the $35^{\text {th }}$ and $36^{\text {th }}$ minutes (fraction highlighted in black, Figure 1A). The further separation of this fraction was carried out on the same column to collect the asterisk peak (Figure 1B). This step was repeated until the end of the sampling. This asterisk peak was utilized for testing the proximate homogeneity of the peptide (Figure 1C). MALDI-TOF MS analysis was used for peptide investigation, which showed a $[\mathrm{M}+\mathrm{H}]^{+}$species, detected at $\mathrm{m} / \mathrm{z}$ 1095.27, that characterized a toxin with molecular mass of 1094.26 Da. Following total reduction with TCEP, the $[\mathrm{M}+\mathrm{H}]^{+}$ species was detected at $m / z$ 1099.31, which indicated the presence of two disulfide bonds in Bn5a (net increase of $1 \mathrm{Da}$ for each cysteine involved in a disulfide bridge, Figure 2).

\section{Primary structure determination}

The primary structure was preliminarily investigated by the MS/MS technique, using CID fragmentation that generated predominantly $b$ - and $y$-type product ions. Figure 3 showed the CID mass spectra of completely reduced peptide. This spectrum of $m / z 1099.31$ parent ions revealed its fragmentation in the series of $b$ - and $y$-type ions, from position 1 to position 9. From the differences between the most intense product ions of $b$-type series $\left(b_{1}\right.$ to $\left.b_{7}\right)$, the initial tag of the sequence was characterized as GCC(L/I)VR. There was an ambiguity in distinguishing between Leu and Ile residues (mass of 113 $\mathrm{Da}$ ) at position 5. Following this initial tag and after the Glu (E), and Cys (C) residues were determined, respectively, through differences between the product ions $b_{7} / b_{8}$ and $b_{8} /$ $b_{9}$. Based on the mass analysis and the combination of the theoretical monoisotopic mass, we inferred an Asn residue at the $\mathrm{N}$-terminus and a Cys residue (not amidated) at the C-terminus of the peptide. The product ions of the $y$-type series $\left(y_{1}\right.$ to $\left.y_{9}\right)$ were all observed with lower signal intensity than $b$-type series. Thus, the initial sequence assignment of $\mathrm{m} / z 1099.31$ parent ion was NGCC(L/I)VRECC exhibiting a cysteine framework $\mathrm{V}\left(-\mathrm{C}_{1} \mathrm{C}_{2}-\mathrm{C}_{3} \mathrm{C}_{4}-\right)$ of the T-superfamily of conopeptides, which is denominated $\mathrm{Bn} 5 \mathrm{a}$ according to the nomenclature of conotoxins [11]. The monoisotopic molecular mass of Bn5a $(1094,26)$ matched well with the calculated theoretical data $(1094,37)$.
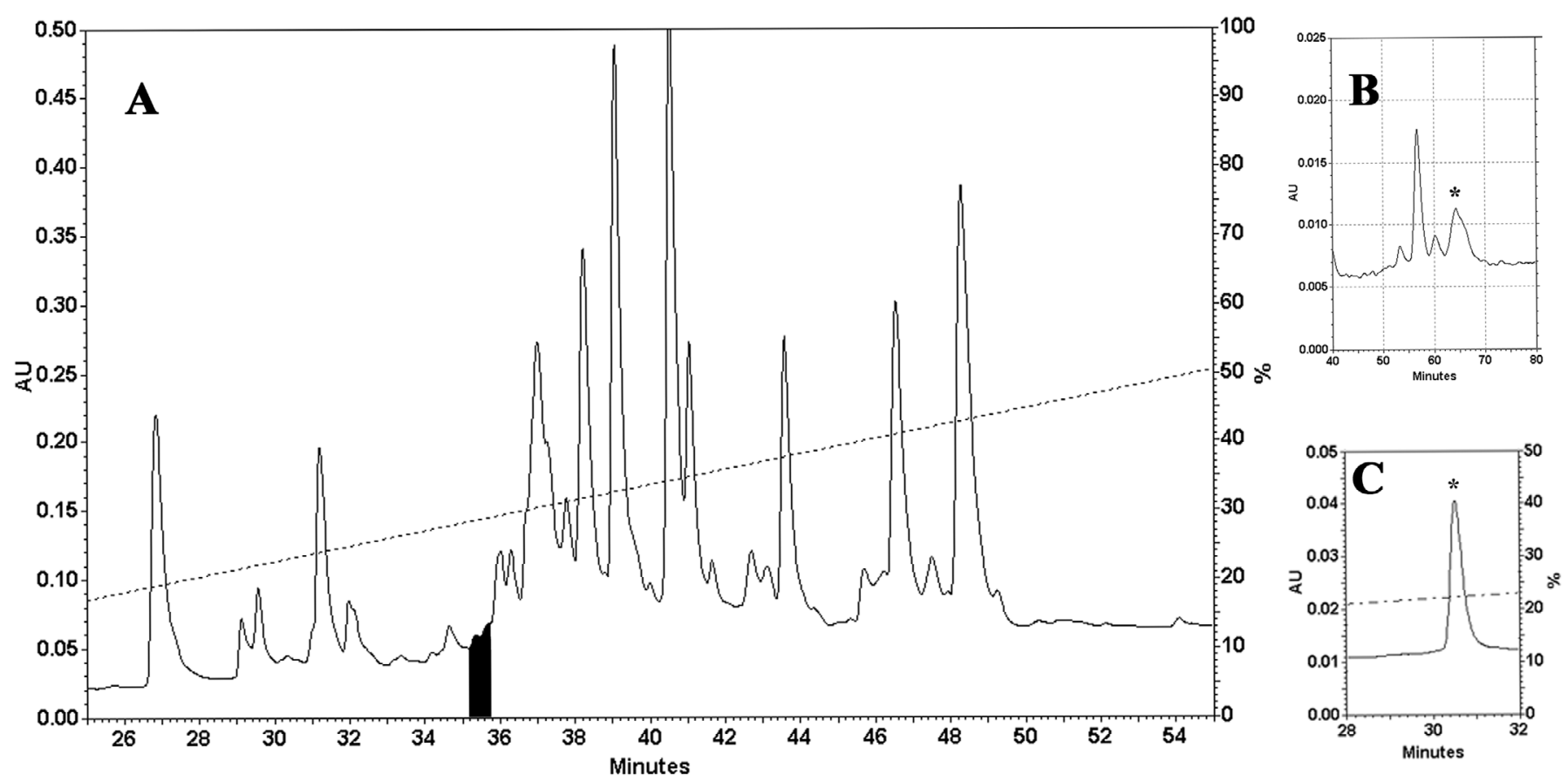

Figure 1. Isolation of novel peptide from C. bandanus venom. (A) RP-HPLC profile of C. bandanus venom. (B) Separation of the fraction highlighted in black. (C) Homogeneity inspection of the asterisk peak. 
Automated Edman sequencing of the native peptide confirmed the peptide-sequencing result and yielded an unambiguous 10-residue sequence (Figure 4) with 4-phenylthiohydantoin (PTH)-cysteine residues at positions 3, 4, 9 and 10, which were
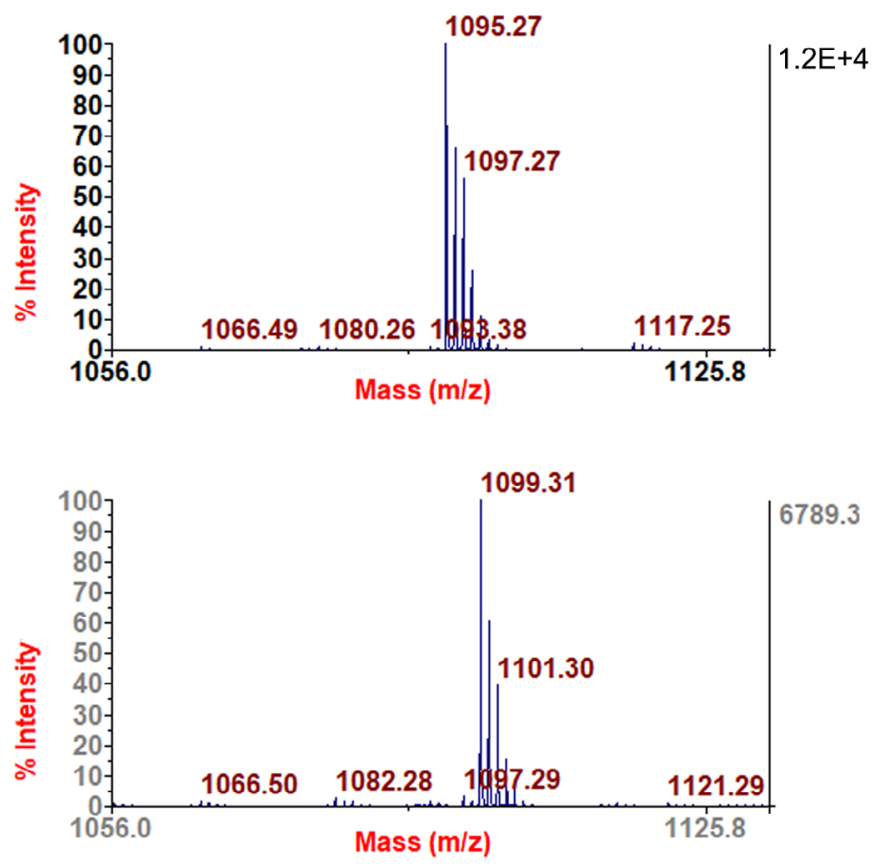

Figure 2. Determination of the cysteine number in the investigated native conopeptide p2.4.2 (upper graph) and in its reduced form by TCEP (lower graph) from off-line LC MALDI-TOF MS. Note the shift of $4 \mathrm{Da}$ characterizing the reduction of two disulfide bonds. not recorded in this method but were identified by MALDI TOF/TOF CID MS/MS. At position 5, we could confirm the isoleucine residue having an amount of $\sim 500 \mathrm{pmol}$ in place of leucine. Thus, sequence Bn5a has a total of 10 amino acids with two disulfide bridges and a free $\mathrm{C}$-terminal Cys residue. The complete linear Bn5a sequence is NGCCIVRECC.

\section{Disulfide connectivities}

The native Bn5a conotoxin was partially reduced and immediately followed by alkylation with IAA in $0.5 \mathrm{M}$ Tri-acetate, $2 \mathrm{mM}$ Na2-EDTA buffer (see in the methods section). Through this approach, alkylation was affected by IAA resulting in a mass increase of $58 \mathrm{Da}$ per sulfhydryl group. The differentially labeled peptide fractions were separated and collected on a $\mathrm{C}_{18} \mathrm{Vydac}$ analytical column (see Additional file 1). We obtained seven peaks with different retention times on the analytical $\mathrm{C}_{18}$ column. Among them were three partially labeled peaks (at 35, 38.5 and 39 minutes), in which one cysteine bridge remains intact $\left([\mathrm{M}+\mathrm{H}]^{+}\right.$species detected at $\mathrm{m} / z$ 1211.1). However, the $39^{\text {th }} \mathrm{min}$ fraction was so small that we were unable to characterize its structure further. Two remaining fractions were then entirely reduced by TCEP. After that, they were desalted on a $\mathrm{C}_{18}$ ZipTip column and then subjected to MS analysis and CID MS/MS fragmentation.

Figure 5 shows the CID MS/MS spectra of the two possible rapidly alkylated species $\left([\mathrm{M}+\mathrm{H}]^{+}=1213.45 \mathrm{Da}\right)$, which predominantly generated $b$-and $y$-type ions. Figure $5 \mathrm{~A}$ showed that the species contained $\mathrm{C}_{1}$ and $\mathrm{C}_{4}$, which were modified with IAA through $b_{2} / y_{8}-b_{3} / y_{7}$ and $b_{9} / y_{1}$ ions. The other species possessed $\mathrm{C}_{2}$ and $\mathrm{C}_{3}$, which were modified with IAA (Figure

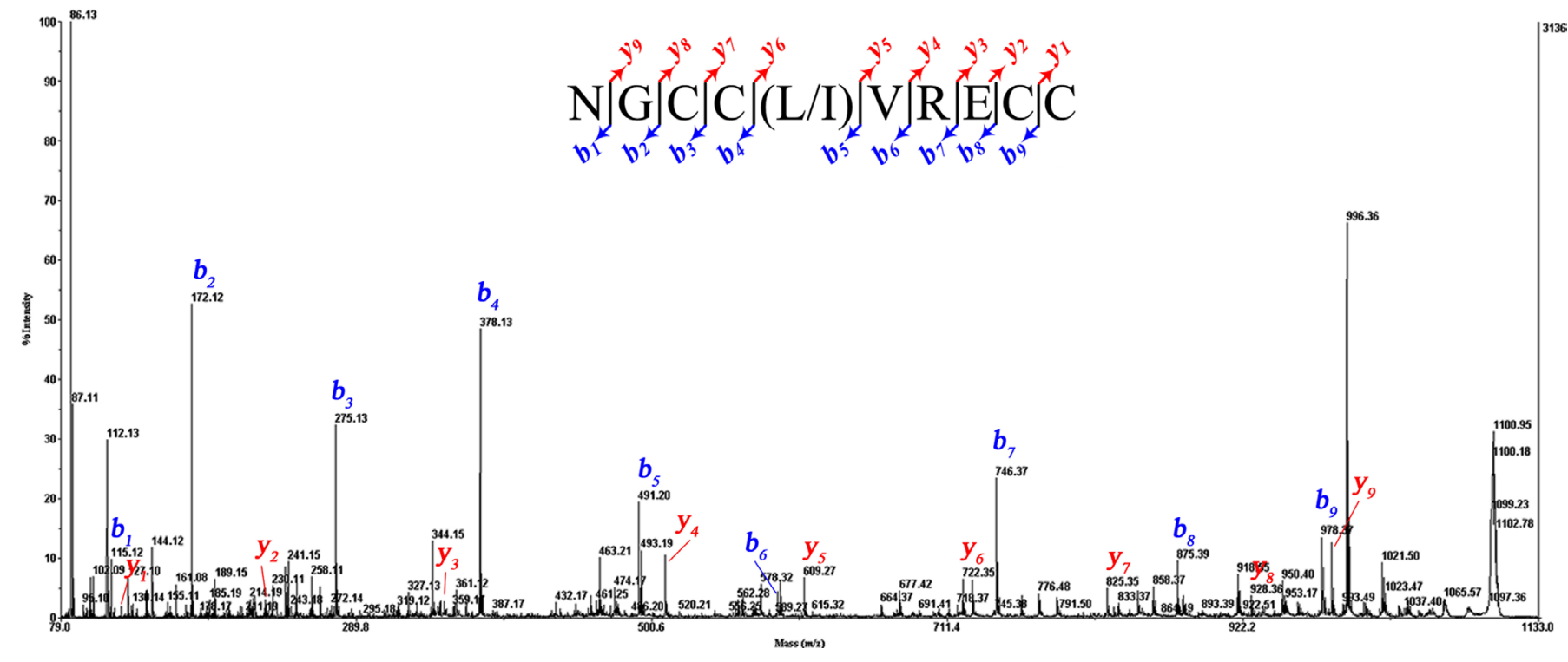

Figure 3. Primary structure determination of CID mass spectrum profile of reduced-Bn5a form, recorded with the MALDI-TOF/TOF 4800 mass spectrometer: The inset shows the sequence derived from these MS/MS spectra. Note $\mathrm{m} / \mathrm{z} 86.13$ corresponds to the immonium ion of Leu or lle. 


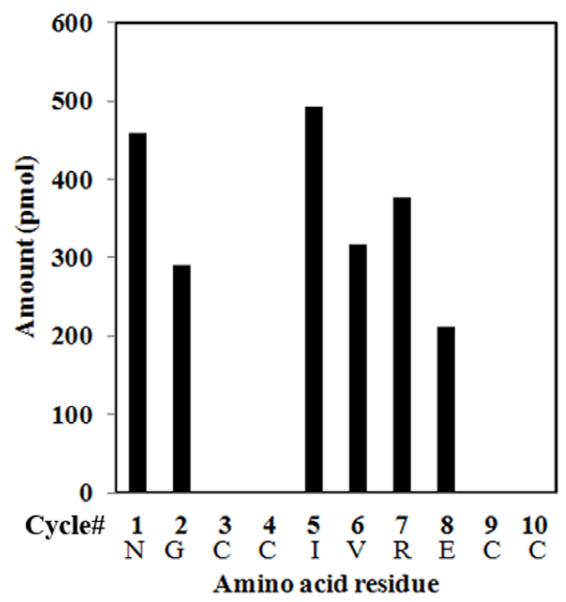

Figure 4. Solid-phase Edman degradation of native Bn5a.
5B) through $b_{3} / y_{7}-b_{4} / y_{6}$ and $b_{8} / y_{2}-b_{9} / y_{1}$ ions. It is worth noting that performing rapid partial reduction-alkylation procedures generated not only completely alkylated species but also species having three alkylated-cysteine scramblings that could be separated on the $\mathrm{C}_{18}$ analytical column (see Additional file 2). Furthermore, two differently modified species shared almost total commonality of fragments, but some essential fragment ions, such as $b_{9}-/ y_{1}$-ions, were distinguishable and are displayed clearly in Figure 6.

Figure 7 provides an overview of this approach adopted and shows the essential fragments, which permit the unambiguous determination of the cysteine connectivities. Both possible rapidly alkylated species with the same $m / z 1213.45$ were identifiable. These data confirm that the disulfide bonds in the Bn5a conopeptide are $\mathrm{C}_{1}-\mathrm{C}_{4}$ and $\mathrm{C}_{2}-\mathrm{C}_{3}$.
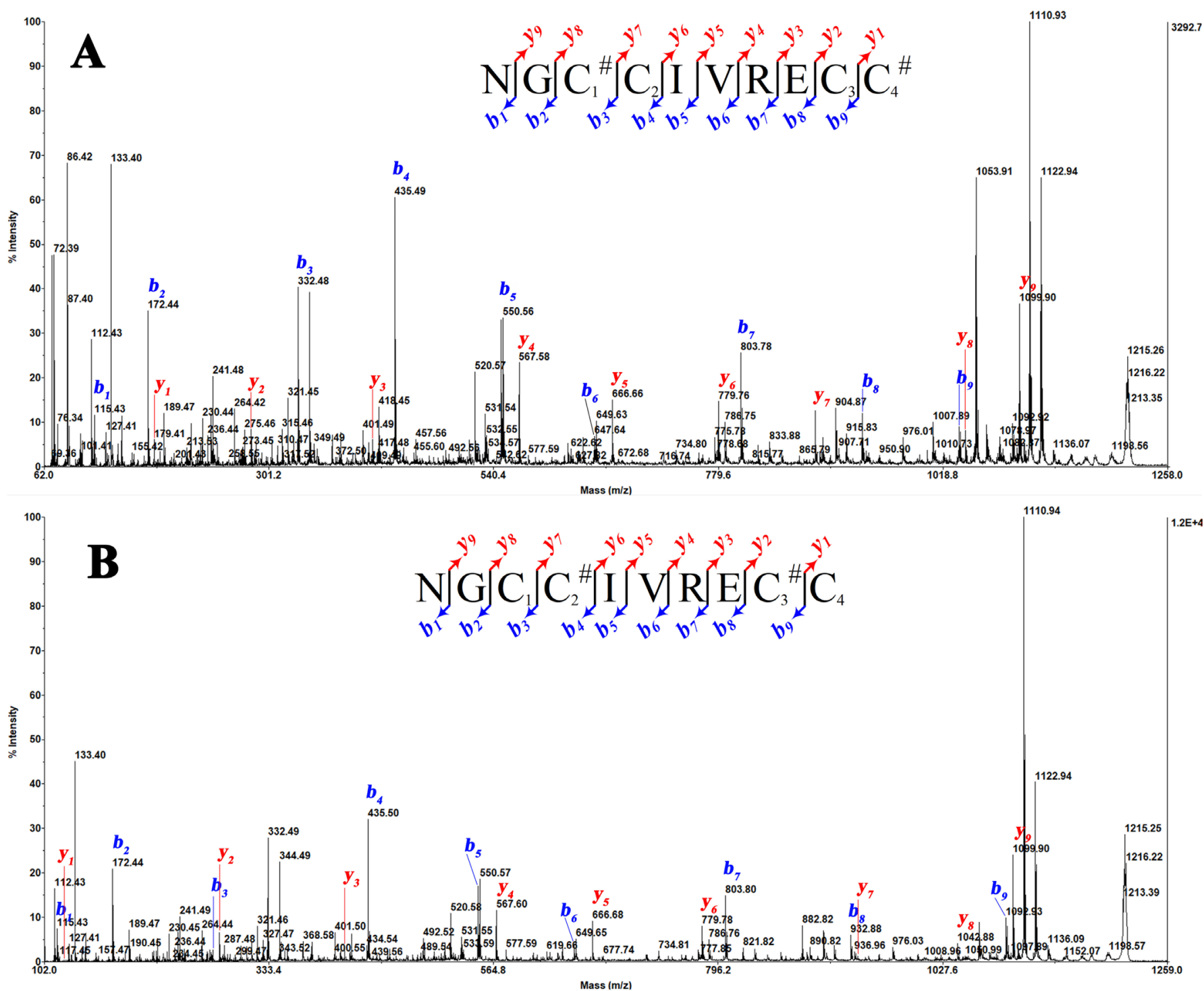

Figure 5. Determination of Bn5a-cysteine connectivity. (A) $\mathrm{CID}$ mass spectrum of $\mathrm{C}_{1}-\mathrm{C}_{4}$ IAA-labeled $\mathrm{Bn} 5 \mathrm{a}$ and $(\mathbf{B}) \mathrm{C}_{2}-\mathrm{C}_{3}$ IAA-labeled Bn5a from experiments partially reduced by alkylation. Note \#: alkylated cysteine by IAA. 

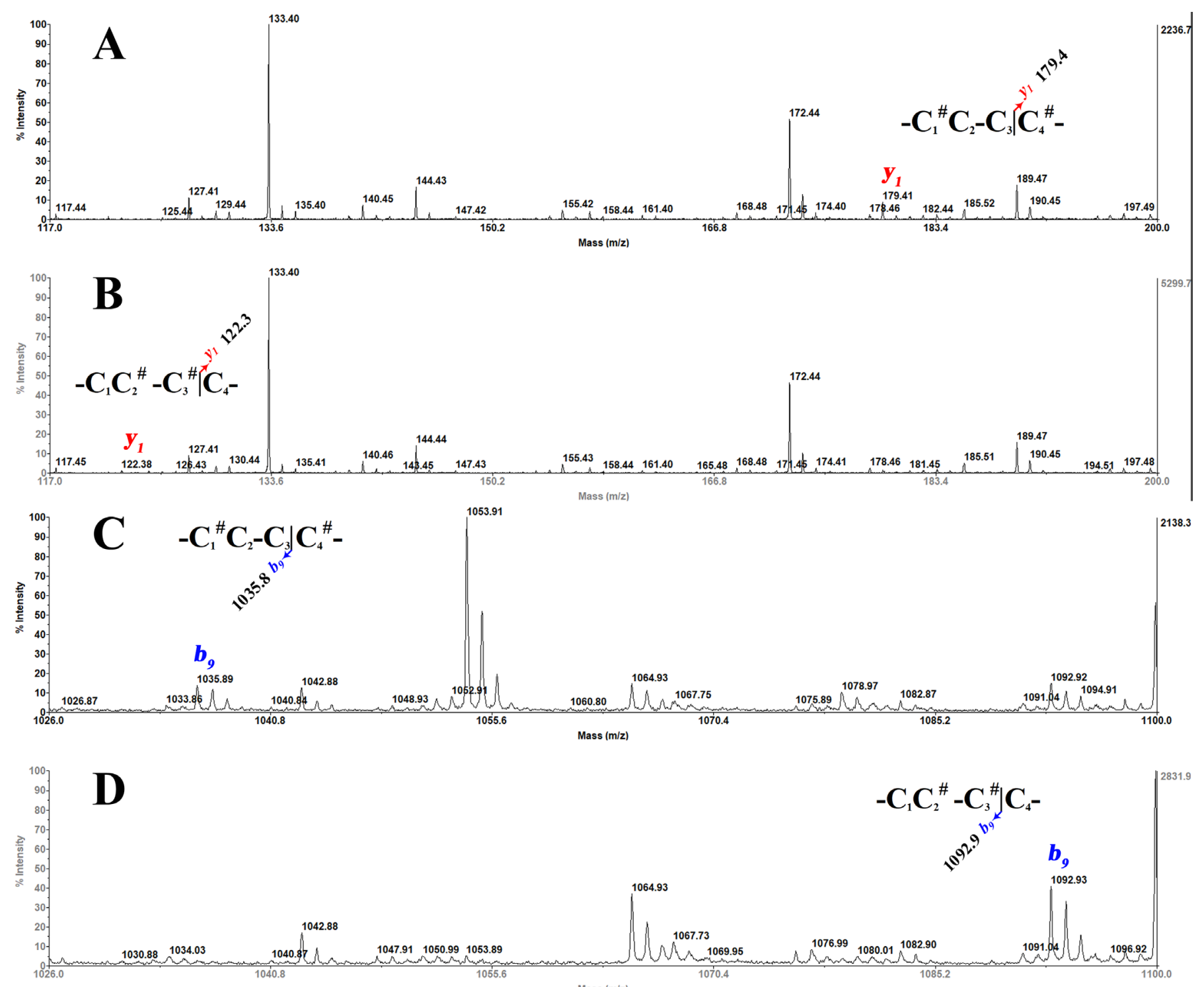

Figure 6. Close-up of the key fragment ions between two modified species in the determination of Bn5a cysteine-connectivity: $A$ portion of the CID mass spectrum of $\mathrm{C}_{1}-\mathrm{C}_{4}$ IAA-labeled $\mathrm{Bn5a}(\mathbf{A}, \mathbf{C})$ and $\mathrm{C}_{2}-\mathrm{C}_{3}$ IAA-labeled $\mathrm{Bn} 5 \mathrm{a}$ (B, D) from experiments partially reduced by alkylation. (A, B) Edited between $\mathrm{m} / \mathrm{z}$ 117 and 200, showing $y_{1}$-ions; (C, D) edited between $\mathrm{m} / \mathrm{z} 1026$ and 1100, showing $b_{9}$-ions. Note \#: alkylated cysteine by IAA.

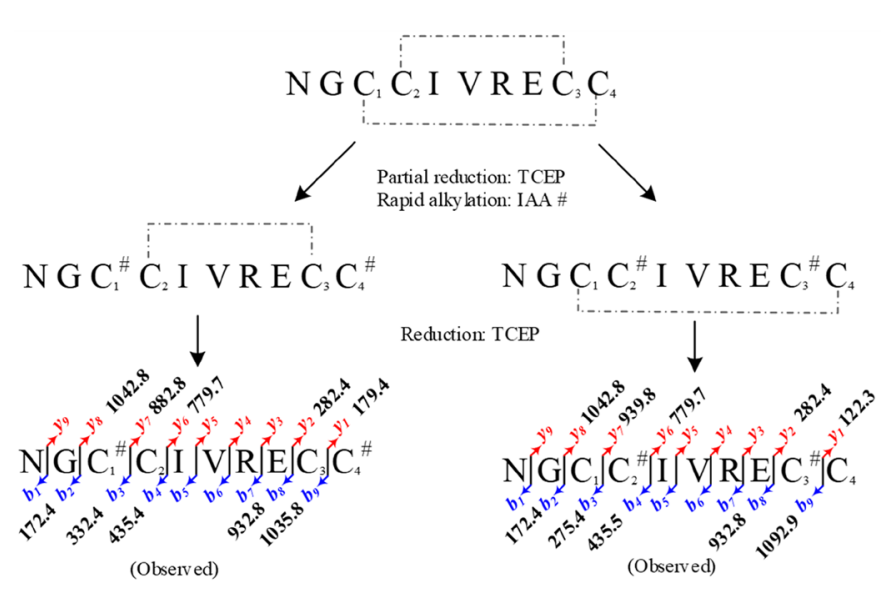

Figure 7. Overview of Bn5a-cysteine connectivity determination and highlight of the key fragments.

\section{Discussion}

A homology comparison reveals that the sequence of Bn5a belongs to the T-superfamily, more specifically, T1-subfamily conotoxins (Table 1). This class of conotoxins has a common feature of the presence of CC-motif at the $\mathrm{N}$ - or C-termini of the molecule. These conotoxins in Table 1 possess four residues presented between the CC pair, isolated from all three species-based diet types, in which the majority of snails are molluscivorous or vermivorous. So far, 19 known sequences possess the $-\mathrm{CC}-\mathrm{x}(4)-\mathrm{CC}-$ motif, while three conotoxins (Bn5a, MrVA, Mo1274) share a common feature, namely the presence of a CC pair at the C-terminus of the molecule. Remarkably, Mo1274 is a bromotryptophan-containing conopeptide, isolated from the venom of a vermivorous Conus monile [12]. This Bn5a peptide is the first T1-conotoxin isolated from C. bandanus 
Table 1. T1-subfamily conopeptides, isolated from different Conus species

\begin{tabular}{|c|c|c|c|c|}
\hline & Name & Organism (diet) & Mature sequence & Reference \\
\hline 1 & $\mathrm{Bn} 5 \mathrm{a}$ & C. bandanus $(\mathrm{m})^{\mathrm{b}}$ & NGCC I VRECC & This work \\
\hline 2 & MrVA & C. marmoreus (m) & NACC I VRQCC & {$[15]$} \\
\hline 3 & $\operatorname{Mr} 5.6$ & C. marmoreus (m) & NGCCRAGDCCS & {$[16]$} \\
\hline 4 & Qc5.1 & C. quercinus (v) & GCC ARLTCCV & {$[17]$} \\
\hline 5 & Pu5.2 & C. pulicarius (v) & GCCEDKT CCFI* & {$[18]$} \\
\hline 6 & Ca5.4 & C. caracteristicus (v) & CCPNKP CCFI & [17] \\
\hline 7 & VcVA & C. victoriae $(\mathrm{m})$ & CCPGKOCCRI* & {$[19]$} \\
\hline 8 & G5.4 & C. geographus (p) & DCCEERWCCF & {$[20]$} \\
\hline 9 & Ts-011 & C. tessulatus (v) & GCCEDKTCCFI* & {$[21]$} \\
\hline 10 & Qc5.2 & C. quercinus (v) & GCCAMLTCCV & {$[17]$} \\
\hline 11 & TXMRCL-03 & C. textile (m) & NCCRRQ ICCGRPS & [21] \\
\hline 12 & Vc5.7 & C. victoriae $(\mathrm{m})$ & ECCEDGWCCTAAPLTAP & {$[22]$} \\
\hline 13 & LeDr192 & C. litteratus (v) & ECCEDGWCCTAAPLT** & [23] \\
\hline 14 & TxVA & C. textile $(\mathrm{m})^{\mathrm{a}}$ & ECCEDGWCCTAAO & {$[24]$} \\
\hline 15 & Pu5.3 & C. pulicarius (v) & SCCP E EPCCFW & [18] \\
\hline 16 & $\mathrm{Pn}-\mathrm{B} 02$ & C. pennaceus (m) & ECCSDGWCCPA* & [21] \\
\hline 17 & TeAr193 & C. textile $(\mathrm{m})$ & NCCRRQ ICCGRT & {$[23]$} \\
\hline 18 & Vc5.9 & C. victoriae $(\mathrm{m})$ & RNCCRLQ I CCGRT & {$[22]$} \\
\hline 19 & Mo1274 & C. monile $(\mathrm{v})^{\mathrm{a}}$ & GNWWCCSARV CC* & {$[12]$} \\
\hline
\end{tabular}

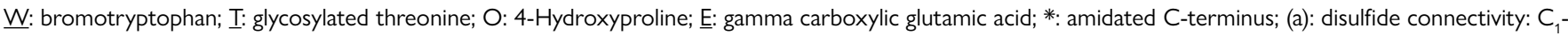
$\mathrm{C}_{3} / \mathrm{C}_{2}-\mathrm{C}_{4}$; (b): disulfide connectivity: $\mathrm{C}_{1}-\mathrm{C}_{4} / \mathrm{C}_{2}-\mathrm{C}_{3}$. $(\mathrm{m})$ : molluscivorous type; (v): vermivorous type; (p): piscivorous type.

venom. There is a notable exception for Bn5a and MrVA (from another mollusk-hunting C. marmoreus venom), which share $80 \%$ apparent homology on the protein sequence level. The reason for high consensus could be relatively close species from both conchological and phylogenetic perspectives between $C$. bandanus and C.marmoreus [13,14].

So far, the T-superfamily conotoxins found in the venom ducts of all three feeding types of Conus include four cysteine frameworks, specifically " $\mathrm{C}_{1} \mathrm{C}_{2}-\mathrm{C}_{3}-\mathrm{C}_{4}$ ” (I), " $\mathrm{C}_{1} \mathrm{C}_{2}-\mathrm{C}_{3} \mathrm{C}_{4}$ ” (V), " $\mathrm{C}_{1} \mathrm{C}_{2}-\mathrm{C}_{3}-\mathrm{C}_{4}$ " (X) and " $\mathrm{C}_{1}-\mathrm{C}_{2}-\mathrm{C}_{3} \mathrm{C}_{4}$ " (XVI) [4,5]. Among them, T1-conotoxins with framework $\mathrm{V}$ possess 1-3, 2-4 cysteine connectivities, while both framework-X and framework-I conotoxins present 1-4 and 2-3 cysteine pairings. However, there were no data on disulfide connectivities for frameworks XVI. The Bn5a possesses four Cys residues and two disulfide bridges resulting in three possible disulfide pairing patterns, namely $\mathrm{C}_{1}-\mathrm{C}_{3} / \mathrm{C}_{2}-\mathrm{C}_{4}, \mathrm{C}_{1}-\mathrm{C}_{4} / \mathrm{C}_{2}-\mathrm{C}_{3}$ and $\mathrm{C}_{1}-\mathrm{C}_{2} / \mathrm{C}_{3}-\mathrm{C}_{4}$. It may be noted that the $\mathrm{C}_{1}-\mathrm{C}_{2} / \mathrm{C}_{3}-\mathrm{C}_{4}$ arrangement, which requires disulfide formation between contiguous Cys residues, is relatively rare.

Echterbille et al. [25] observed the partial reduction of conopeptides having two disulfide bridges (using TCEP $400 \mu \mathrm{M}$ for $30 \mathrm{~min}$ at $\mathrm{pH} 4.5$ or 2) to assign disulfide bridge arrangements. This approach could lead to the scrambling of disulfides in the observed peptides. Herein, we used a rapid partial-reduction/ alkylation procedure to characterize the native fold of Bn5a. It is said that our method is the same as that of Echterbille et al.
[25], but in contrast we applied partial reduction in a shorter time ( $2.5 \mathrm{~min}$ vs. $30 \mathrm{~min})$. We performed the partial reduction at $\mathrm{pH} 3$ for $2.5 \mathrm{~min}$ and immediately alkylated by saturated IAA in the buffer solution ( $\mathrm{pH} \sim 8.0$ ) to maximally prevent interchange and/or reoxidation. The disulfide scrambling phenomenon, in our opinion, is impossible in the alkylation step. A small number of species may present disulfide scrambling in the rapid partial reduction procedure. Thus, we observed this scrambling at the 39-min peak (see Additional file 1).

Fortunately, we successfully collected two isomers. Each of isomers contained one disulfide bond and two alkylated cysteines at the 35- and 38.5-min peaks. The disulfide connectivities of the 35-min peak had been proven with the pattern $C^{\#} \mathrm{C}$ $\mathrm{CC}^{\#}$ (Figure 5A) while the connectivities of the 38.5-min peak presented the $C C^{\#}-C^{\#} C$ pattern (Figure $5 B$ ). From these results, the reaction time of rapid partial reduction should be reduced to $1-1.5 \mathrm{~min}$. It could help to decrease the number of reduced species and disulfide-scrambling species. Furthermore, the alkaline condition of the alkylation step should also be adjusted to the acidic condition ( $\mathrm{pH} 2-3$ ) to prevent the reduction of remaining disulfide bond(s) of peptides.

Of the 19 listed sequences of T1-conotoxins possessing the -CC-x(4)-CC- motif, the cysteine connectivity has been established only in the case of three peptides, including the peptide investigated in the present work. The $\mathrm{Bn} 5 \mathrm{a}$ belonged to framework $\mathrm{V}\left(\mathrm{C}_{1} \mathrm{C}_{2}-\mathrm{C}_{3} \mathrm{C}_{4}\right)$. However, it possessed only $\mathrm{C}_{1}-\mathrm{C}_{4} /$ 
$\mathrm{C}_{2}-\mathrm{C}_{3}$ cysteine connectivities unlike the reported conopeptides sharing the same framework V (1-3, 2-4 cysteine connectivities), such as Mo1274 and TxVA. Additionally, it shared the same disulfide pairing of conopeptides of the frameworks I and X, namely MrIA, MrIB [26] and CMrX [27], respectively (Figure 8), while chi-MrIA is a 13-residue peptide in the C. marmoreus venom that had been found to act as antidepressant inhibitors of the norepinephrine transporter (NET) in both mice and humans [28].

$\mathrm{CMrX}$ conotoxin caused breathing difficulty, flaccid paralysis, and death in 2 hours at the dose $12.6 \mu \mathrm{g} / \mathrm{g}$ of body weight. Figure 8 displays the alignment analysis with high homology, hydrophobicity, charged distribution of $\mathrm{Bn} 5 \mathrm{a}$ conotoxin and three other bioactive conotoxins [29]. The sequences Bn5a and MrIA share the most common physicochemical properties that could induce the same cysteine connectivities. It is suggested that Bn5a may target the NET. This transporter is widely expressed in the human nervous system and plays an essential role in regulating norepinephrine signaling and homeostasis by transporting synaptically released norepinephrine back into the presynaptic neuron [30]. Dysregulation of the removal of norepinephrine by NET is associated with many neuropsychiatric diseases such as depression, anxiety disorders, attention deficit hyperactivity disorder, and epilepsy [31]. Further investigation of the biological activity of this unique conotoxin may reveal its pharmacological properties.

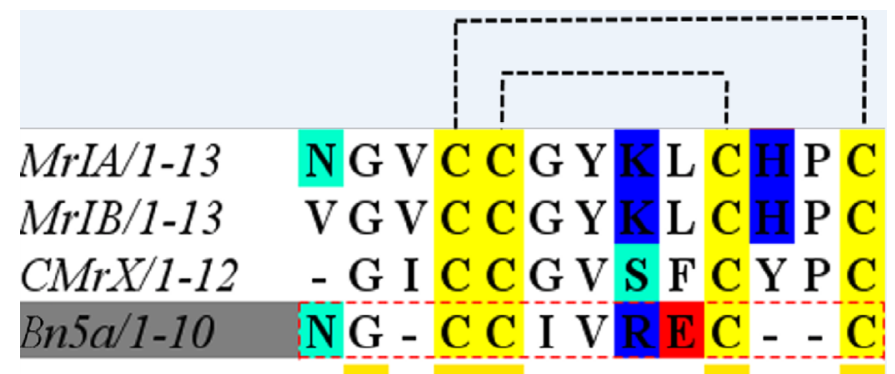

\section{Conservation}

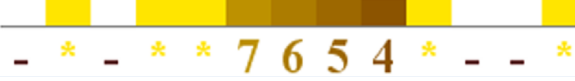

Figure 8. Multiple sequence alignment of $\mathrm{Bn} 5 \mathrm{a}$ and three other bioactive compounds with different cysteine frameworks: Residue conservation score was calculated via the software Jalview v2.8. The dotted line indicates disulfide connectivity. Gaps have been presented to optimize the alignment sequence identity. Color coding employs the following scheme: hydrophobic residues are in white, negatively charged residues in red, positively charged residues in blue, polar uncharged residues in green, and cysteine residues in yellow. The color intensity and the "conservation index" score (1-11) reflect the conservation of physicochemical properties of amino acids in the particular column of the alignment. *conserved column (where the highest score is 11).

\section{Conclusion}

In summary, the purification and mass spectral characterization of a novel peptide, $\mathrm{Bn} 5 \mathrm{a}$, isolated from the venom of a molluscivorous snail, C. bandanus, were described. The primary structure NGCCIVRECC of the peptide was determined through de novo sequencing by tandem mass spectrometry and subsequently by Edman degradation. Based on a determination of the cysteine framework, intervening residues, and homology comparison, Bn5a was classified in the T1-subfamily of conotoxins. This peptide was the first T1-conotoxin isolated from the C. bandanus venom. Moreover, Bn5a possessed $-\mathrm{C}_{1} \mathrm{C}_{2}-$ $\mathrm{x}(4)-\mathrm{C}_{3} \mathrm{C}_{4}$ - pattern belonging on the framework $\mathrm{V}$ but exhibited special $\mathrm{C}_{1}-\mathrm{C}_{4} / \mathrm{C}_{2}-\mathrm{C}_{3}$ disulfide connectivities that differed from the disulfide connectivity patterns in other T1-conotoxins of the framework $\mathrm{V}\left(\mathrm{C}_{1}-\mathrm{C}_{3} / \mathrm{C}_{2}-\mathrm{C}_{4}\right)$. The difference in structure may suggest a specific property in pharmaceutical function.

\section{Abbreviations}

CID: collision-induced dissociation; HCCA: cyano-4hydroxycinnamic acid; HEPES: 4-(2-hydroxyethyl)-1piperazineethanesulfonic acid; HPLC: reversed-phase highperformance liquid chromatography; IAA: iodoacetamide; MALDI: matrix-assisted laser desorption/ionization; MS/MS: tandem mass spectrometry; MS: mass spectrometry; Na2-EDTA: ethylenediaminetetraacetic acid disodium salt dihydrate; NET: norepinephrine transporter; PTH: phenylthiohydantoin; TCEP: tris (2-carboxyethyl) phosphine; TFA: Trifluoroacetic acid; TOF: time of flight.

\section{Acknowledgements}

We would like to thank The Biodiversity Conservation Agency in Khanh Hoa for permitting us to collect Conus species from Khanh Hoa Bay. The authors are grateful to Dr. Bui Tran Nu Thanh Viet from the Department of Postharvest Technology (Nha Trang University) for the fruitful discussions and suggestions. We are thankful to Nguyen Van Suu, Tran Thi Thu Thoa from the Institute of Biotechnology and Environment (Nha Trang University, Vietnam) for the specimen preparation.

\section{Availability of data and materials}

The data used and/or analyzed during the study are available from the corresponding author upon reasonable request.

\section{Funding}

This research was funded by Vietnam National Foundation for Science and Technology Development (NAFOSTED) under grant number 106-NN.02-2015.14.

\section{Competing interests}

The authors declare that they have no conflict of interest.

\section{Author's contributions}

NB supervised the entire project, participated in analyzing of the results, and wrote the initial draft. JPLC did spectrometry analysis and participated in data interpretation. NDN designed 
the experiments and contributed to writing the manuscript. PTKV participated in fractionation and peptide purification. All authors read and approved the final manuscript.

\section{Ethics approval}

The present study was approved by the Research Ethics Committee of Nha Trang University and NAFOSTED. Permission number: 40/QĐ-HĐQL-NAFOSTED 12/4/2016. The cone snails were collected with the permission of Biodiversity Conservation Agency supported by Vietnam Environmental Administration, an autonomous agency linked to the Ministry of Natural Resources and Environment.

\section{Consent for publication}

Not applicable

\section{Supplementary material}

The following online material is available for this article:

Additional file 1. RP-HPLC profile of rapid partial reductionalkylation procedure of Bn5a peptide. Note: $[\mathrm{M}+\mathrm{H}]^{+}$of $\mathrm{Bn} 5 \mathrm{a}$ with four alkylations: $1327.21 \mathrm{Da} ; \mathrm{M}+\mathrm{H}]^{+}$of Bn5a with three alkylations: $1270.2 \mathrm{Da} ;[\mathrm{M}+\mathrm{H}]^{+}$of Bn5a with two alkylations and one bridge: $1211.1 \mathrm{Da} ;[\mathrm{M}+\mathrm{H}]^{+}$of native Bn5a: 1095.14 Da.

Additional file 2. Spectra of the Bn5a species having three alkylated-cysteines at $32^{\text {nd }} \mathrm{min}$ (upper graph) and $34^{\text {th }}$ min (lower graph).

\section{References}

1. Lewis RJ, Dutertre S, Vetter I, Christie MJ. Conus venom peptide pharmacology. Pharmacol Rev. 2012 Apr;64(2):259-98.

2. Lebbe EK, Tytgat J. In the picture: disulfide-poor conopeptides, a class of pharmacologically interesting compounds. J Venom Anim Toxins incl Trop Dis. 2016 Nov 7;22:30. doi: 10.1186/s40409-016-0083-6.

3. Kaas Q, Westermann JC, Halai R, Wang CK, Craik DJ. ConoServer, a database for conopeptide sequences and structures. Bioinformatics. 2008 Feb;24(3):445-6.

4. Kaas Q, Yu R, Jin AH, Dutertre S, Craik DJ. ConoServer: updated content, knowledge, and discovery tools in the conopeptide database. Nucleic Acids Res. 2012 Jan;40:D325-30.

5. Petrel C, Hocking HG, Reynaud M, Upert G, Favreau P, Biass D, et al. Identification, structural and pharmacological characterization of tau$\mathrm{CnVA}$, a conopeptide that selectively interacts with somatostatin sst3 receptor. Biochem Pharmacol. 2013 Jun 1;85(11):1663-71.

6. Liu J, Wu Q, Pi C, Zhao Y, Zhou M, Wang L, et al. Isolation and characterization of a T-superfamily conotoxin from Conus litteratus with targeting tetrodotoxinsensitive sodium channels. Peptides. 2007 Dec;28(12):2313-9.

7. Rigby AC, Lucas-Meunier E, Kalume DE, Czerwiec E, Hambe B, Dahlqvist I, et al. A conotoxin from Conus textile with unusual posttranslational modifications reduces presynaptic Ca2+ influx. Proc Natl Acad Sci U S A. 1999 May 11;96(10):5758-63.

8. Wang S, Du T, Liu Z, Wang S, Wu Y, Ding J, et al. Characterization of a T-superfamily conotoxin TxVC from Conus textile that selectively targets neuronal nAChR subtypes. Biochem Biophys Res Commun. 2014 Nov 7;454(1):151-6.

9. Nguyen B, Le Caer JP, Aráoz R, Thai R, Lamthanh H, Benoit E, et al. Isolation, purification and functional characterization of alpha-BnIA from Conus bandanus venom. Toxicon. 2014 Dec;91:155-63.
10. Gray WR. Disulfide structures of highly bridged peptides: a new strategy for analysis. Protein Sci. 1993 Oct;2(10):1732-48.

11. Olivera BM, Cruz LJ. Conotoxins, in retrospect. Toxicon. 2001 Jan;39(1):7-14.

12. Nair SS, Nilsson CL, Emmett MR, Schaub TM, Gowd KH, Thakur SS, et al. De novo sequencing and disulfide mapping of a bromotryptophancontaining conotoxin by Fourier transform ion cyclotron resonance mass spectrometry. Anal Chem. 2006 Dec 1;78(23):8082-8.

13. Nam HH, Corneli PS, Watkins M, Olivera B, Bandyopadhyay P. Multiple genes elucidate the evolution of venomous snail-hunting Conus species. Mol Phylogenet Evol. 2009 Dec;53(3):645-52.

14. Röckel D, Korn W, Kohn AJ. Manual of the Living Conidae, Volume 1 Indo-Pacific Region: 1-517. Hackenheim Verlag Christa Hemmen. 1995.

15. Han YH, Wang Q, Jiang H, Miao XW, Chen JS, Chi CW. Sequence diversity of T-superfamily conotoxins from Conus marmoreus. Toxicon. 2005 Mar 15;45(4):481-7.

16. Dutertre S, Jin AH, Kaas Q, Jones A, Alewood PF, Lewis RJ. Deep venomics reveals the mechanism for expanded peptide diversity in cone snail venom. Mol Cell Proteomics. 2013 Feb;12(2):312-29.

17. Walker C, Shetty R, Olivera BM, Hooper D, Jacobsen R, STEEL D, et al. Tau-conotoxin peptides. Google Patents; 2000.

18. Peng $C$, Wu X, Han Y, Yuan D, Chi C, Wang C. Identification of six novel T-1 conotoxins from Conus pulicarius by molecular cloning. Peptides. 2007 Nov;28(11):2116-24.

19. Jakubowski JA, Keays DA, Kelley WP, Sandall DW, Bingham JP, Livett $B G$, et al. Determining sequences and post-translational modifications of novel conotoxins in Conus victoriae using cDNA sequencing and mass spectrometry. J Mass Spectrom. 2004 May;39(5):548-57.

20. Hu H, Bandyopadhyay PK, Olivera BM, Yandell M. Elucidation of the molecular envenomation strategy of the cone snail Conus geographus through transcriptome sequencing of its venom duct. BMC Genomics. 2012;13:284.

21. Conticello SG, Gilad Y, Avidan N, Ben-Asher E, Levy Z, Fainzilber M. Mechanisms for evolving hypervariability: the case of conopeptides. Mol Biol Evol. 2001 Feb;18(2):120-31.

22. Luo $\mathrm{S}$, Zhangsun $\mathrm{D}$, Zhang $\mathrm{B}$, Chen $\mathrm{X}$, Feng J. Direct cDNA cloning of novel conotoxins of the T-superfamily from Conus textile. Peptides. 2006 Nov;27(11):2640-6.

23. Luo $S$, Zhangsun $D, W u$ Y, Zhu $X, X i e ~ L, ~ H u ~ Y$, et al. Identification and molecular diversity of T-superfamily conotoxins from Conus lividus and Conus litteratus. Chem Biol Drug Des. 2006 Aug;68(2):97-106.

24. Walker CS, Steel D, Jacobsen RB, Lirazan MB, Cruz LJ, Hooper $\mathrm{D}$, et al. The T-superfamily of conotoxins. J Biol Chem. $1999 \mathrm{Oct}$ 22;274(43):30664-71.

25. Echterbille J, Quinton L, Gilles N, Pauw E De. Ion mobility mass spectrometry as a potential tool to assign disulfide bonds arrangements in peptides with multiple disulfide bridges. Anal Chem. 2013;85:4405.

26. Sharpe IA, Gehrmann J, Loughnan ML, Thomas L, Adams DA, Atkins A, et al. Two new classes of conopeptides inhibit the alpha1-adrenoceptor and noradrenaline transporter. Nat Neurosci. 2001 Oct;4(9):902-7.

27. Balaji RA, Ohtake A, Sato K, Gopalakrishnakone P, Kini RM, Seow KT, et al. lambda-conotoxins, a new family of conotoxins with unique disulfide pattern and protein folding. Isolation and characterization from the venom of Conus marmoreus. J Biol Chem. 2000 Jan;275(50):39516-22.

28. Sharpe IA, Palant E, Schroeder Cl, Kaye DM, Adams DJ, Alewood PF, et al. Inhibition of the norepinephrine transporter by the venom peptide chiMrIA. Site of action, $\mathrm{Na}+$ dependence, and structure-activity relationship. J Biol Chem. 2003 Oct 10;278(41):40317-23.

29. Livingstone $C D$, Barton $G$ J. Protein sequence alignments: a strategy for the hierarchical analysis of residue conservation. Comput Appl Biosci. 1993Dec;9(6):745-56

30. Galli A, DeFelice LJ, Duke BJ, Moore KR, Blakely RD. Sodium-dependent norepinephrine-induced currents in norepinephrine-transportertransfected HEK-293 cells blocked by cocaine and antidepressants. J Exp Biol. 1995 Oct;198(Pt 10):2197-212.

31. Stöber G, Nöthen MM, Pörzgen P, Brüss $M$, Bönisch H, Knapp M, et al. Systematic search for variation in the human norepinephrine transporter gene: Identification of five naturally occurring missense mutations and study of association with major psychiatric disorders. Am J Med Genet. 1996 Nov 22;67(6):523-32. 